\title{
Factors Affecting Students' Acceptance of e-Learning Environments in Developing Countries: A Structural Equation Modeling Approach
}

\author{
Ali Tarhini, Kate Hone, and Xiaohui Liu
}

\begin{abstract}
A number of studies have shown that e-learning implementation is not simply a technological solution, but a process of many different factors such as social and behavioural contexts. Yet little is known about the important rule of such factors in technology adoption and use in the context of developing countries such as Lebanon. Therefore, the main objective of our study is to empirically validate an extended Technology Acceptance Model (TAM) (to include Social Norms and Quality of Work Life constructs) in the Lebanese context.

A quantitative methodology approach was adopted in this study. To test the hypothesized research model, data were collected from 569 undergraduate and postgraduate students studying in Lebanon via questionnaire. The collected data were analysed using structural equation modeling (SEM) technique based on AMOS methods and in conjunction with multi-group analysis. As hypothesized, the results of the study revealed perceived usefulness (PU), perceived ease of use (PEU), social norms (SN) and Quality of Work life (QWL) to be significant determinants of students' behavioral intention (BI). This provides support for the applicability of the extended TAM in the Lebanese context. Implications to both theory and practice of this study are discussed at the end of the paper.
\end{abstract}

Index Terms-Technology acceptance, TAM, e-learning, structural equation modeling

\section{INTRODUCTION}

During the last two decades, with the widespread use of the World Wide Web (WWW), universities and other educational institutions have been investing in information systems (such as Moodle, Blackboard and WebCT) to support both face-to-face and remote course delivery [1]-[2].

Although the internet is considered as a global technology, the efficiency of such tools should also be measured locally since users usually work in local/national contexts [3]. This is more crucial especially in developing countries such as Lebanon where universities and higher education institutions support traditional styles of pedagogy in education due to the lack of financial resources or trained staff [4]-[6] which in turn affect the acceptance of technology within such countries.

The successful implementation of e-learning tools depends on the perception of the users and also their knowledge and skills in using computers. Such major factors have been shown to affect users' initial acceptance of computer

Manuscript received October 19, 2012; revised December 15, 2012.

Ali Tarhini, Kate Hone, and Xiaohui Liu are with the Department of Information System, Brunel University, England (email: Ali.Tarhini@Brunel.ac.uk,

XiaoHui.Liu@Brunel.ac.uk). technology and their future behaviour regarding the usage of web-based learning systems [7]-[8].

Due to its acceptable explanatory power and popularity, many studies have used the Technology Acceptance Model (TAM) in the technology acceptance and adoption literature in the IS implementation area [9] and especially in e-learning context [10]-[17].

However, it is unclear whether the model holds for e-learning in developing countries and Arabic countries are particularly under-researched. TAM's reliability and validity and thus its generalizability are still questionable as it was criticised for its cultural bias especially when tested in non-western countries [18]-[19]. Additionally, TAM suffers from other limitations such as inconsistencies in previous studies and is still questionable in explaining the social influence on the acceptance of technology [18], [20]-[22]. To address these limitations, this study will extend TAM to include other determinants such as social norms and quality of work life [9], [23]-[24].

The main aims of the current study are to address the above limitations. Specifically, our research focuses on the factors that affect student's acceptance and usage of web-based learning systems in Arab culture, particularly in Lebanon as a cultural context and Blackboard as a web-based learning system.

This paper is organized as follows: In the next section, research model and a summary of the literature review in the field of e-learning system acceptance are provided. In section three, the methodology that guided the research is described. The data collection analysis and results are then described in Section four. Finally, Section four concludes the paper with the main findings.

\section{THEORETICAL FRAMEWORK}

This paper proposes and tests a conceptual model of e-learning technology acceptance based on TAM, drawing from previous literature that used TAM in an educational context. Additionally, the model extends TAM through the inclusion of Subjective Norms (SN) and Quality of Working Life (QWL) as additional predictor variables. The overall conceptual model is illustrated in Figure 1 and the sections which follow explain and justify each of the predicted relationships in light of previous findings from the literature.

\section{A. Perceived Ease of Use and Perceived Usefulness}

Many researchers have used the TAM to measure students' acceptance of Web-based learning tools [12], [25]-[29]. For example, Amoako-Gyampah [25] found that the perceived 
ease of use (PEOU) has a direct and positive influence and effects on the intention to use the system, and his result were also supported by other researchers [12], [28]. In contrast, Chesney [26] concluded that PEOU did not have a direct and significant influence on the intention to use the system

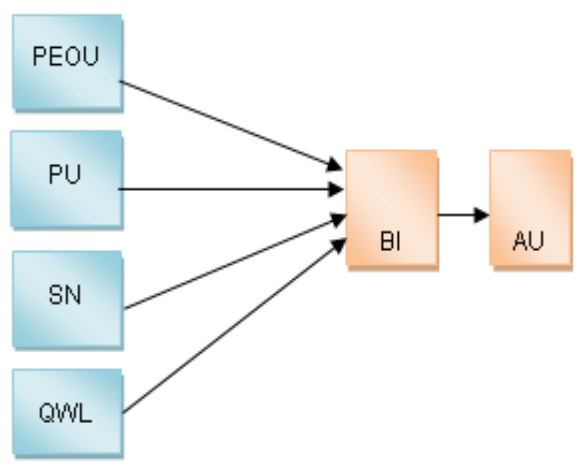

Fig. 1. Research model

Reviewing the literature, several studies in the educational context have been found to be inconsistent. Some claim that PEOU had a significant influence on the intention to use the system [16], [27]. Another two studies by Saade \& Galloway [27] and Landry et al. [29] considered the student's usage of Web-based learning using the TAM and found that both Perceived ease of use and Perceived usefulness are the determinants for the system usage. They suggest that if students perceive an e-learning tool (in this case Blackboard) to be easy to use, they would also perceive the tool to be useful. All the subsequent studies about student perceptions on using technologies support Davis's (1989) model. In addition, perceived usefulness were found the most influential variable in predicting the intention to use the web-based learning system in TAM [12, 16] while Saeed [14] found that PU has an influence on the intention to use but was not the most influential factor. Moreover, literature shows that studies using TAM and models derived from TAM [22, 30] demonstrated that there is a relationship between PU and PEOU and behavioural intention in the acceptance and adoption of technology. Therefore, it is hypothesized that:

H1: Perceived Usefulness will have a direct positive influence on the intention to use web-based learning in the Lebanese sample.

H2: Perceived Ease of Use will have a direct positive influence on the intention to use web-based learning system in the Lebanese sample

\section{B. Social Norm Impact Usage Behaviour}

Social norm was adopted and included in the TAM model, in order to overcome the limitation of TAM in measuring the influence of social environments [22]. SN is defined as the person's perception that most people who are important to him or her think he or she should or should not perform the behaviour in question [31]. SN was studied in some research as an antecedent of BI and in other studies as an antecedent PU. However, as mentioned by Venkatesh et al. [32] the influence of $\mathrm{SN}$ is very complex,

This research assumes the effect of SN on BI is highly considered in the Lebanese context. The rationale is based on the cultural index which proposed by Hofstede (1980), He indicated that power distance (PD) and Masculinity (M/F) are high and Individualism (I/C) is low in Lebanon. SN is particularly crucial in a multi-religious, multi-ethnic country like Lebanon.

There was some inconsistency in the literature about the influence of SN on the intention to use the technology. For example, many researchers found a significant impact of SN on BI [22], [32]-[35], while a number of others failed to find any impact [36-38]. Building on Venkatesh and Davis [22] research, this study will consider only the direct impact of SN on BI. Davis [30] omitted the social norms construct from the original TAM, however SN was added later in TAM2 due to its importance in explaining the external influence of others on the behaviour of an individual. Therefore, $\mathrm{SN}$ will be measured by the influence of instructors and other colleagues on students' perception to use the web-based learning system. Thus, we propose the following hypothesis:

H3: social norms will have a positive influence on student's behavioural intention to use and accept the e-learning technology

\section{Quality of Work Life}

Quality of Work Life (QWL) was included based in some previous empirical studies in IS in order to extend and improve the TAM model [23]-[24], [39]. However, it has not previously been considered within an educational context. In this paper, QWL is defined in terms of students' perception and belief that using the technology will improve their quality of work life such as saving expenses when downloading e-journals, or in communication when using email to communicate with their instructors and friends. Therefore, it is hypothesised that:

H4: QWL will have a positive influence on student's behavioural intention to use the web-based learning system.

\section{Behavioural Intentions for Using an E-Learning System}

The presence of behavioural intention (BI) in the TAM is one of the major differences with TRA. BI is considered to be an immediate antecedent of usage behaviour and gives an indication about an individual' readiness to perform a specific behaviour. In TAM, both PU and PEOU influence an individual's intention to use the technology, which in turn influence the usage behaviour [30]. There were many supports in the literature for the relationship between BI and usage behaviour in general [22], [32-[33], this has recently been extended to the e-learning context [10-14], [16]-[17]. Therefore, we propose the following hypothesis:

H5: Students' BI will have a positive effect on his or her actual use of web-based learning system

\section{RESEARCh METhodology}

A survey was employed due to its advantages [40]-[42]. This research aims to test hypothesized relationships within the context of technology acceptance in an objective manner where the researcher is isolated from the aim of the study. Additionally, the constructs and their relationships used within the conceptual model were developed and validated thoroughly in the theories and models about the adoption and technology acceptance. Furthermore, this study uses 
Structural Equation Modeling (SEM) technique in order to test hypotheses and moderators and to perform a number of tests such as group comparisons which require a large number of participants. Therefore, using the survey as a data collection method is appropriate from the ontological, epistemological and methodological point of view.

The target sample for this survey was Lebanese web-based learning system users, studying full or part time for Masters or undergraduate degrees (in a number of disciplines) at two universities located in Beirut. Participation was on a voluntary basis and no financial incentive was offered.

The current study, as the majority of empirical research in technology acceptance, has used a non-probability convenience sampling technique as it enables the researcher to collect data from the participants based on their availability. It also helps the researcher to improvise with the resource available for the research especially when there is lack of time and financial resources. A total of 1000 self-administered questionnaires were distributed to the students, the number of returned questionnaires were 640 indicating a $64 \%$ response rate. We also excluded the incomplete questionnaires which resulted in 596 valid questionnaires. Additionally, all the items (questions) used by this research have been drawn from the literature, where they were quoted to be reliable and valid to measure constructs of the phenomena that they intend to represent (see Appendix A)

In the present study, the convenience sampling method was employed. This method is the most commonly used method in behavioural and social science studies. It allows the researcher to select the sample subjects from the targeted population based on who are willing and easily accessible to be recruited in the research. It is also the least expensive, least time-consuming among all other techniques

\section{RESULTS}

\section{A. Sample Descriptive Analysis}

TABLE I: PROFILE OF THE RESPONDENTS

\begin{tabular}{|l|l|c|c|}
\hline $\begin{array}{l}\text { Demographic } \\
\text { Characteristic }\end{array}$ & & Freq & \% \\
\hline Gender & Male & 306 & 53.8 \\
& Female & 263 & 46.2 \\
\hline Age & Younger $<=22$ & 410 & 72.4 \\
& Older $>23$ & 157 & 27.6 \\
\hline Educational Level & Undergraduate & 365 & 64.1 \\
& Postgraduate & 204 & 35.9 \\
\hline Blackboard & No-Exp & 57 & 10 \\
Experience & Some-Exp & 220 & 38.7 \\
& Experienced & 292 & 51.3 \\
\hline Internet and & Novice & 89 & 15.6 \\
Computer & Moderate & 254 & 44.6 \\
Experience & Expert & 226 & 39.7 \\
\hline Number of Courses & $1-2$ & 217 & 38.1 \\
using Blackboard & $3-5$ & 249 & 43.8 \\
& $>5$ & 103 & 18.1 \\
\hline
\end{tabular}

Table I presents the demographic characteristics of the respondents. A total of 596 participants took part in the study. The sample's age range varied from 17 to 35 years old, with
$64.1 \%$ (366 participants) undergraduates and 35.9\% (204 participants) postgraduates; their self-rated Web-based learning experience was either some or experienced, with either an intermediate or expert level in using the Internet. Males represent $53.8 \%$ (306 participants) of the sample and females represent $46.2 \%$ (263 participants).

Also the descriptive statistics showed that the majority of participants indicate positive responses to the constructs that are measured in this study (See Table II). All means were greater than 5 for the independent variables (PEOU, PU, SN and QWL) and 4.21 for the dependent variables (BI and AU). This comes as a surprise as the previous literature suggests that Web-based learning system in Lebanon is still in its infancy [4]-[6].

TABLE II: DESCRIPTIVE STATISTICS OF THE CONSTRUCTS

\begin{tabular}{|c|c|c|c|}
\hline Construct & Mean & Std Deviation & $\begin{array}{c}\text { Cronbach } \\
\text { Alfa }\end{array}$ \\
\hline PEOU & 5.26 & 1.06429 & .903 \\
\hline PU & 5.172 & 1.098 & .905 \\
\hline SN & 4.96 & 1.16888 & .757 \\
\hline QWL & 5.2 & 1.00151 & .835 \\
\hline BI & 4.78 & 1.13233 & .868 \\
\hline AU & 4.217 & 1.01527 & .657 \\
\hline
\end{tabular}

\section{B. The Structural Model Analysis and Hypothesis Testing}

Structural equation modeling was used to test all the hypothesized relationships (See Table III). The estimated values of fit indices have shown the good structural model fit to the data for the proposed research model in this study (See Fig. 2). This is clear from the table that all values were in the recommended range.

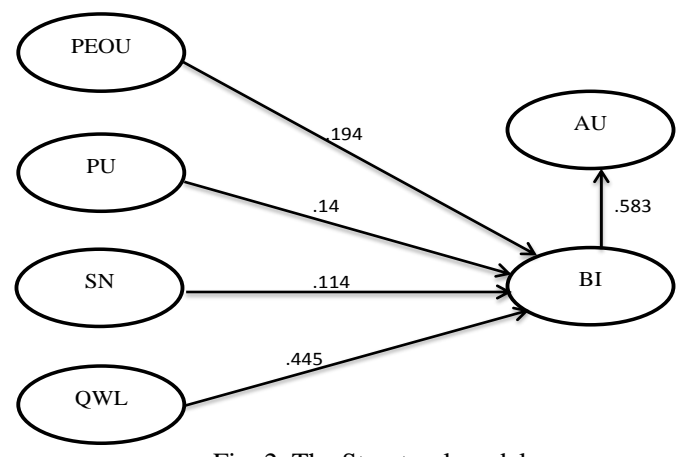

Fig. 2. The Structural model

TABLE III: THE SUMMARY OF DIRECT HYPOTHESIZED RESULTS

\begin{tabular}{|l|l|l|l|l|}
\hline H\# & $\begin{array}{l}\text { Proposed } \\
\text { Relationship }\end{array}$ & $\begin{array}{l}\text { Effects } \\
\text { Type }\end{array}$ & $\begin{array}{l}\text { Path } \\
\text { coefficient }\end{array}$ & $\begin{array}{l}\text { Study } \\
\text { Results }\end{array}$ \\
\hline H1 & PEOU $\rightarrow$ BI & $\begin{array}{l}\text { Direct } \\
\text { effect }\end{array}$ & $0.194 * * *$ & Supported \\
\hline H2 & PU $\rightarrow$ BI & $\begin{array}{l}\text { Direct } \\
\text { effect }\end{array}$ & $0.143 * *$ & Supported \\
\hline H3 & SN $\rightarrow$ BI & $\begin{array}{l}\text { Direct } \\
\text { effect }\end{array}$ & $0.114 * * *$ & Supported \\
\hline H4 & QWL $\rightarrow$ BI & $\begin{array}{l}\text { Direct } \\
\text { effect }\end{array}$ & $0.445^{* * *}$ & Supported \\
\hline H5 & BI $\rightarrow$ AU & $\begin{array}{l}\text { Direct } \\
\text { effect }\end{array}$ & $0.583 * * *$ & Supported \\
\hline \multicolumn{5}{|l|}{ Notes: $* \mathrm{p}<0.05 ; * * \mathrm{p}<0.01 ; * * * \mathrm{p}<0.001$} \\
\hline
\end{tabular}

As can be shown in Table III, all the direct hypotheses were supported. PU $\left(\beta=0.143^{* *}, \mathrm{p}<0.01\right)$ and PEOU 
$(ß=0.194 ; \mathrm{p}<0.001)$ were found to have a significance positive influence on behavioural intention to use web-based learning system, supporting $\mathrm{H} 1$ and H2. It should be noted that students were found to be highly affected by their colleagues and instructors in using technology, SN to have a high significance, and $\mathrm{SN}(\beta=0.114 ; \mathrm{p}<0.001)$ to support $\mathrm{H} 3$. Moreover, Behavioural Intention was also influenced by the quality of work life $(\beta=0.445 ; \mathrm{p}<0.001)$, supporting $\mathrm{H} 4$. Furthermore, the results also show that Actual Usage is influenced by Behavioural Intention $(\beta=0.583$; $p<0.001)$ which supports H5.

\section{DISCUSSION AND CONCLUSION}

The research question of this study is focused on the factors that affect the acceptance and usage of web-based learning systems in Lebanon. A conceptual model that extends the TAM to include social norms and quality of work life constructs as main determinants was proposed. This research is therefore the first to find empirical support for these relationships in the Lebanese context. Our results show that all the direct relationship between PEOU, PU, SN, and QWL with BI (with $40.2 \%$ of its variance explained) and also BI with UB were supported. These results are very close to traditional TAM as proposed by Davis [30].

Different from most of the studies that consider western countries, our study supports TAM's reliability and validity in an educational context in the developing world and more specifically in Lebanon. Our results revealed that e-learning is well accepted in Lebanon despite potential problems mentioned earlier

Although TAM and other user acceptance models have been validated empirically, research continues to add social factors to overcome the limited explanatory power of such models. This study moves in that direction. By including social norms and quality of work life as main dominants, we can describe and understand how the students make their decisions about using and adopting web-based learning system. Our study empathised that e-learning implementation should focus more on the social contexts rather than the technological solution.

\section{APPENDIX}

A. SURVEY ITEMS AND SCALES

\begin{tabular}{|c|c|c|c|}
\hline Construct & Item & Question & Source \\
\hline $\begin{array}{l}\text { Perceived Usefulness } \\
(P U)\end{array}$ & $\begin{array}{l}\text { PU1 } \\
\text { PU2 } \\
\text { PU3 PU4 } \\
\text { PU5 }\end{array}$ & $\begin{array}{l}\text { Using the Web-based learning system will } \\
\text {...allow me to accomplish learning tasks more quickly } \\
\text {...improve my learning performance } \\
\text {...make it easier to learn course content } \\
\text {...increase my learning productivity } \\
\text {...enhance my effectiveness in learning }\end{array}$ & {$[2,30,43,44]$} \\
\hline $\begin{array}{l}\text { Perceived Ease Of } \\
\text { Use (PEOU) }\end{array}$ & $\begin{array}{l}\text { PEOU1 } \\
\text { PEOU2 } \\
\text { PEOU3 } \\
\text { PEOU4 } \\
\text { PEOU5 }\end{array}$ & $\begin{array}{l}\text { Learning to operate the Web-based learning system is easy for me. } \\
\text { I find it easy to get the Web-based learning system to do what I want } \\
\text { it to do. } \\
\text { My interaction with Web-based learning system is clear and } \\
\text { understandable. } \\
\text { It is easy for me to become skillful at using the Web-based learning } \\
\text { system } \\
\text { I find the Web-based learning system easy to use }\end{array}$ & {$[2,30,43,44]$} \\
\hline Subjective Norm (SN) & $\begin{array}{l}\text { SN1 } \\
\text { SN2 } \\
\text { SN3 } \\
\text { SN4 }\end{array}$ & $\begin{array}{l}\text { My Instructors thinks that I should participate in the Web-based } \\
\text { learning activities. } \\
\text { Other students think that I should participate in the Web-based } \\
\text { learning activities. } \\
\text { Management of my university thinks that I should use the } \\
\text { Web-based leaning activities. } \\
\text { Generally speaking, I would do what my instructor thinks I should } \\
\text { do. }\end{array}$ & {$[22,32,45]$} \\
\hline $\begin{array}{l}\text { Perceived Quality of } \\
\text { work life }(Q W L)\end{array}$ & $\begin{array}{l}\text { QWL1 } \\
\text { QWL2 } \\
\text { QWL3 } \\
\text { QWL4 } \\
\text { QWL5 }\end{array}$ & $\begin{array}{l}\text { The freedom to get the course information any time of the day will } \\
\text { helps me to have more time for a creative thinking and leisure. } \\
\text { Using the free resources such as web-based learning system and } \\
\text { e-libraries helped me to save money and effort. } \\
\text { Using the Web-based learning system provide more opportunities to } \\
\text { participate in the class. } \\
\text { Using emails to communicate with other student groups help me to } \\
\text { save my expense and effort. } \\
\text { Overall, using the Web-based learning help improving my quality of } \\
\text { working life. }\end{array}$ & {$[23,39]$} \\
\hline $\begin{array}{l}\text { Behavioural } \\
\text { intention (BI) }\end{array}$ & $\begin{array}{l}\mathrm{BI} 2 \\
\mathrm{BI} 3\end{array}$ & $\begin{array}{l}\text { Given the chance, I intend to use the Web-based learning system to } \\
\text { do different things, from downloading lecture notes and } \\
\text { participating in chat rooms to learning on the Web. } \\
\text { I predict I would use web-based learning system in the next } \\
\text { semester. } \\
\text { In general, I plan to use Web-based learning system frequently for } \\
\text { my coursework and other activities in the next semester }\end{array}$ & {$[43,46,47]$} \\
\hline $\begin{array}{l}\text { Usage Behaviour } \\
\text { (UB) }\end{array}$ & $\begin{array}{l}\text { UB1 } \\
\text { UB2 }\end{array}$ & $\begin{array}{l}\text { On average, how frequently do you use the Web-based system? } \\
\text { On the average working day, how much time do you spend on the } \\
\text { Web-based learning system? }\end{array}$ & {$[30]$} \\
\hline
\end{tabular}




\section{REFERENCE}

[1] K. M. Fletcher, "Self-efficacy as an evaluation measure for programs in support of online learning literacies for undergraduates," The Internet and higher education, 2005, vol. 8, no. 4, pp. 307-322.

[2] E. W. T. Ngai, J. K. L. Poon, and Y. H. C. Chan, "Empirical examination of the adoption of WebCT using TAM," Computers \&amp; Education, 2007, vol. 48, no. 2, pp. 250-267.

[3] N. Li and G. Kirkup, "Gender and cultural differences in Internet use: A study of China and the UK," Computers \& Education, 2007, vol. 48, no. 2, pp. 301-317.

[4] R. Nasser and K. Abouchedid, "Attitudes and concerns towards distance education: the case of Lebanon," Online Journal of Distance Learning Administration, 2000, vol. 3, no. 4, pp. 1-10.

[5] UNDP, United Nations Development Program, Arab Human Development Report, New York, 2002.

[6] F. Baroud and K. Abouchedid, "e-Learning in Lebanon: Patterns of E-learning Development in Lebanon's Mosaic Educational Context," in Proc. of e-learning practices: cases on challenges facing e-learning and national development, institutional studies and practices, 2010, Eskisehir-Turkey, Anadolu University, pp. 409-424.

[7] K. Kim and J. Moore, "Web-based learning: Factors affecting student' satisfaction and learning experience," First Monday, 2005, vol. 10, no. 11.

[8] G. H. Jones and B. H. Jones, "A comparison of teacher and student attitudes concerning use and effectiveness of web-based course management software," Educational Technology \& Society, 2005, vol. 8, no. 2, pp. 125-135

[9] V. Venkatesh and H. Bala, "Technology acceptance model 3 and a research agenda on interventions," Decision Sciences, 2008, vol. 39, no. 2, pp. 273-315.

[10] S. Zhang, J. Zhao, and W. Tan, "Extending TAM for online learning systems: An intrinsic motivation perspective," Tsinghua Science \& Technology, 2008, vol. 13, no. 3 pp. 312-317.

[11] C. Yi-Cheng et al., Predicting College Student'Use of E-Learning Systems: an Attempt to Extend Technology Acceptance Model, 2007.

[12] S. C. Chang and F. C. Tung, "An empirical investigation of students' behavioural intentions to use the online learning course websites," British Journal of Educational Technology, 2008, vol. 39, no. 1 pp. 71-83.

[13] S. Y. Park, "An analysis of the technology acceptance model in understanding university students' behavioral intention to use e-learning," Educational Technology \& Society, 2009, vol. 12, no. 3, pp 150-162.

[14] K. A. Saeed and S. Abdinnour-Helm, "Examining the effects of information system characteristics and perceived usefulness on post adoption usage of information systems," Information \& Management, 2008, vol. 45, no. 6, pp. 376-386.

[15] R. McCarthy, "Measuring students perceptions of blackboard using the technology acceptance model: A PLS approach," E-learning, 2006, vol. 26, no. 2, pp. 18 .

[16] I. F. Liu et al., "Extending the TAM model to explore the factors that affect Intention to Use an Online Learning Community," Computers \& Education, 2010, vol. 54, no. 2, pp. 600-610.

[17] G. Walker and N. Johnson, "Faculty intentions to use components for Web-enhanced instruction," International Journal on e-Learning, 2008, vol. 7, no. 1, pp. 133.

[18] S. McCoy, D. F. Galletta, and W. R. King, "Integrating national culture into IS research: the need for current individual level measures," Communications of the Association for Information Systems, 2005, vol. 15 , no. 1 , pp. 12 .

[19] M. Srite and E. Karahanna, "The role of espoused national cultural values in technology acceptance," MIS quarterly, 2006, vol. 30, no. 3, pp. 679-704.

[20] D. Straub, M. Keil, and W. Brenner, "Testing the technology acceptance model across cultures: A three country study," Information \& Management, 1997 , vol. 33, no. 1, pp. 1-11.

[21] D. Gefen and D. W. Straub, "Gender differences in the perception and use of e-mail: An extension to the technology acceptance model," MIS quarterly, 1997, pp. 389-400.

[22] V. Venkatesh and F. D. Davis, "A theoretical extension of the technology acceptance model: Four longitudinal field studies," Management science, 2000, pp. 186-204.

[23] N. Kripanont, Examining a technology acceptance model of internet usage by academics within Thai business schools, Victoria University Melbourne, Australia, 2007.

[24] A. B. Zakour, Cultural differences and information technology acceptance, 2004.
[25] K. Amoako-Gyampah, "Perceived usefulness, user involvement and behavioral intention: an empirical study of ERP implementation," Computers in Human Behavior, 2007, vol. 23, no. 3, pp. 1232-1248.

[26] T. Chesney, An acceptance model for useful and fun information systems, 2006.

[27] R. G. Saadé and I. Galloway, "Understanding intention to use multimedia information systems for learning," Informing Science: International Journal of an Emerging Transdiscipline, 2005, vol. 2, pp. 287-296

[28] S. H. Liu, H. L. Liao, and C. J. Peng, "Applying the technology acceptance model and flow theory to online e-Learning users'acceptance behavior," E-learning, 2005, vol. 4, no. H6, pp. H8.

[29] B. J. L. Landry, R. Griffeth, and S. Hartman, "Measuring studen perceptions of blackboard using the technology acceptance model," Decision Sciences Journal of Innovative Education, 2006, vol. 4, no. 1, pp. 87-99.

[30] F. D. Davis, "Perceived usefulness, perceived ease of use, and user acceptance of information technology," MIS quarterly, 1989, pp. 319-340.

[31] I. Ajzen and M. Fishbein, Understanding attitudes and predicting social behavior, Prentice-Hall, vol. 278, 1980.

[32] V. Venkatesh et al., "User acceptance of information technology: Toward a unified view," MIS quarterly, 2003, pp. 425-478.

[33] S. Taylor and P. Todd, "Decomposition and crossover effects in the theory of planned behavior: A study of consumer adoption intentions,' International journal of research in marketing, 1995, vol. 12, no. 2, pp. 137-155.

[34] V. E. M. Raaij and J. J. L. Schepers, "The acceptance and use of a virtual learning environment in China," Computers \& Education, 2008, vol. 50 , no. 3 , pp. $838-852$.

[35] V. Venkatesh and M. G. Morris, "Why don't men ever stop to ask for directions? Gender, social influence, and their role in technology acceptance and usage behavior," MIS quarterly, 2000, pp. 115-139.

[36] M. T. Dishaw and D. M. Strong, "Extending the technology acceptance model with task-technology fit constructs," Information \& Management, 1999, vol. 36, no. 1, pp. 9-21.

[37] P. Y. K. Chau and P. J. Hu, "Examining a model of information technology acceptance by individual professionals: An exploratory study," Journal of Management Information Systems, 2002, vol. 18, no. 4, pp. 191-230.

[38] W. Lewis, R. Agarwal, and V. Sambamurthy, "Sources of influence on beliefs about information technology use: An empirical study of knowledge workers," MIS quarterly, 2003, pp. 657-678.

[39] M. Srite and E. karahanna, "A Cross-Cultural Model of Technology Acceptance," presented at the Annual Diffusion of Innovations Group in Information Technology, Charlotte, NC, 2000.

[40] A. Bryman and E. Bell, Business research methods, Cambridge; New York, NY: Oxford University Press, 2011.

[41] J. Collis and R. Hussey, Business research: a practical guide for undergraduate \& postgraduate students, Basingstoke: PalgraveMacmillan, 2009.

[42] J. W. Creswell, Research design : qualitative, quantitative, and mixed methods approaches, Los Angeles: Sage, 2008.

[43] R. Agarwal and E. Karahanna, "Time flies when you're having fun: cognitive absorption and beliefs about information technology usage 1," MIS quarterly, 2000, vol. 24, no. 4, pp. 665-694.

[44] K. A. Pituch and Y. Lee, "The influence of system characteristics on e-learning use," Computers \& Education, 2006, vol. 47, no. 2, pp. 222-244.

[45] J. Schepers and M. Wetzels, "A meta-analysis of the technology acceptance model: Investigating subjective norm and moderation effects," Information \& Management, 2007, vol. 44, no. 1, pp. 90-103.

[46] M. K. O. Lee, C. M. K. Cheung, and Z. Chen, "Acceptance of Internet-based learning medium: the role of extrinsic and intrinsic motivation," Information \& Management, 2005, vol. 42, no. 8, pp 1095-1104.

[47] J. W. Moon and Y. G. Kim, "Extending the TAM for a World-Wide-Web context," Information \& Management, 2001, vol. 38, no. 4 , pp. $217-230$

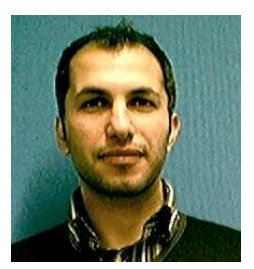

Ali Tarhini is a doctoral candidate in the Department of Information System and Computing at Brunel University, England. He received his M.S in Advanced Web Application Programming from University of Essex in 2008, UK. He also has a B.S in Computer Science from C\&E American University in 2003, Lebanon. His research interests include human-computer interaction, 
cross-cultural aspects of e-learning use in higher educational institutions, cultural effect on behaviors towards Information Systems, E-learning, user adoption and acceptance of technology.

Kate Hone is a reader in Information Systems at Brunel University in West London, England where she is also Deputy Head of the Graduate School. Her research interests include human-computer interaction, cross-cultural issues in IT, affective computing and universal access. She has a BA in Experimental Psychology from the University of Oxford and MSc and $\mathrm{PhD}$ degrees in Human Factors from the University of Birmingham. Her research has been published in journals including the International Journal of Human-Computer Studies, Behaviour and Information Technology, Interacting with Computers, Universal Access in the Information Society, and New Technology, Work and Employment.
Xiaohui Liu has been a professor of Computing at Brunel University since 2000 where directs the Centre for Intelligent Data Analysis, conducting interdisciplinary research concerned with the effective analysis of data. His research interests include the understanding of individual differences in human behavior using data mining and development of novel intelligent data analysis methods for a variety of applications. He has published over 100 papers in leading journals in these areas, including ACM Transactions on ComputerHuman Interaction, Journal of the American Society for Information Science and Technology, IEEE Transactions on Neural Networks, User modeling and User-Adapted Interaction, IEEE Transactions on Systems, Man, and Cybernetics - Part B, Journal of Documentation, and Journal of Information Science. 